\title{
Simulation of Materials Used in the Multiphase Oxygen Reactor of Hydrogen Production $\mathrm{Cu}-\mathrm{Cl}$ Cycle
}

\author{
Mohammed W. Abdulrahman \\ Rochester Institute of Technology \\ Dubai Silicon Oasis, Dubai, UAE \\ mwacad@rit.edu
}

\begin{abstract}
In the thermochemical water splitting process by $\mathrm{Cu}-\mathrm{Cl}$ cycle, oxygen gas is produced by a thermolysis process in a threephase reactor involving molten salt, solid reactant and gaseous oxygen. A precise knowledge of the hydrodynamic and heat transfer analyses are required for the design and scale-up of the multiphase thermolysis reactor. In the experimental studies of the scale up analysis, there are some difficulties and challenges in using the actual materials of the thermolysis reactor products (i.e. molten salt $\mathrm{CuCl}$ and oxygen gas). In this paper, alternative materials are defined, by using dimensional analyses, to simulate the hydrodynamic and heat transfer behaviors of the actual materials. It has been found that these alternative materials are liquid water at $22^{\circ} \mathrm{C}$ and helium gas at $90^{\circ} \mathrm{C}$. The alternative materials provide safe environment for the experimental runs as well as lower operation temperature. Furthermore, these materials are characterized by the availability and low costs. This paper represents a unique tool for testing the hydrodynamic and heat transfer behaviors in a simulated environment prior to the adaption into the thermolysis reactor of the $\mathrm{Cu}-\mathrm{Cl}$ cycle.
\end{abstract}

Keywords: $\mathrm{Cu}-\mathrm{Cl}$ cycle, Hydrogen, Multiphase, Dimensional analysis.

\section{Introduction}

Copper-chlorine $(\mathrm{Cu}-\mathrm{Cl})$ cycle was identified as one of the promising lower temperature cycles (Lewis et al., 2003; Serban et al., 2004). The $\mathrm{Cu}-\mathrm{Cl}$ cycle includes three chemical reactions to decompose water into hydrogen and oxygen. Two of the chemical reactions are thermal and one is an electrochemical reaction. The three reaction steps of the $\mathrm{Cu}-\mathrm{Cl}$ cycle (Fig. 1) are $[1,2,3,4]$;

$$
\begin{array}{lll}
2 \mathrm{CuCl}(\mathrm{a})+2 \mathrm{HCl}(g) \rightarrow 2 \mathrm{CuCl}_{2}(\mathrm{a})+\mathrm{H}_{2}(g) & 100{ }^{\circ} \mathrm{C} & \text { step (1) } \\
2 \mathrm{CuCl}_{2}(s)+\mathrm{H}_{2} \mathrm{O}(\mathrm{g}) \leftrightarrow \mathrm{Cu}_{2} \mathrm{OCl}_{2}(\mathrm{~s})+2 \mathrm{HCl}(\mathrm{g}) & 375^{\circ} \mathrm{C} & \text { step (2) } \\
\mathrm{Cu}_{2} \mathrm{OCl}_{2}(\mathrm{~s}) \rightarrow 2 \mathrm{CuCl}(\mathrm{l})+1 / 2 \mathrm{O}_{2}(g) & 530{ }^{\circ} \mathrm{C} & \text { step (3) }
\end{array}
$$

where $a, s, l$ and $g$ denote to aqueous, solid, liquid and gas respectively. 


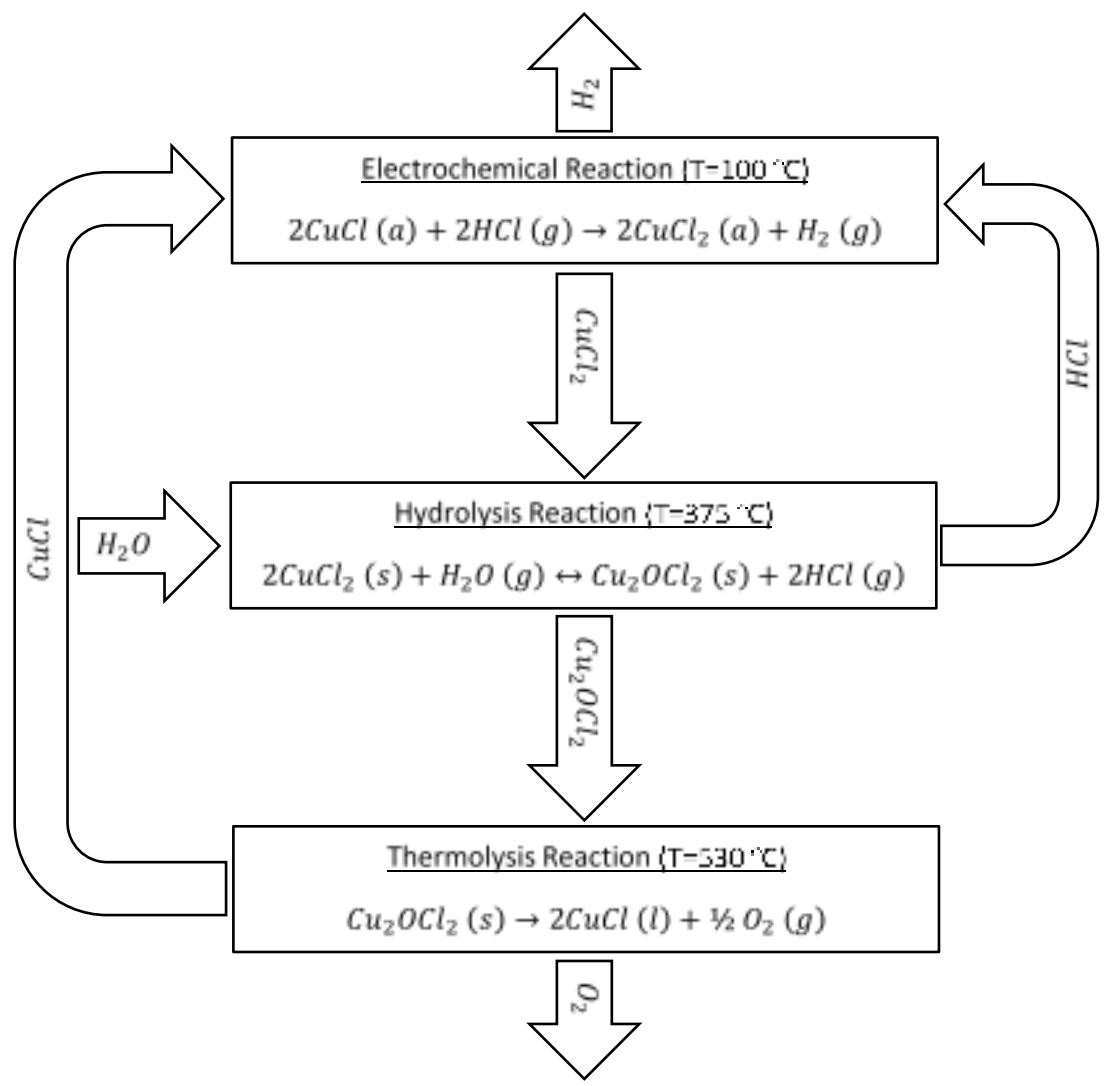

Fig. 1: Three reaction steps of the $\mathrm{Cu}-\mathrm{Cl}$ cycle [4].

In the oxygen production step of the $\mathrm{Cu}-\mathrm{Cl}$ cycle (step 3), a solid copper oxychloride $\left(\mathrm{Cu}_{2} \mathrm{OCl}_{2}\right)$, is decomposed thermally into oxygen gas $\left(\mathrm{O}_{2}\right)$ and molten cuprous chloride $(\mathrm{CuCl})$. The solid $\mathrm{Cu}_{2} \mathrm{OCl}_{2}$ is fed to the oxygen production reactor (thermolysis reactor) from the $\mathrm{CuCl}_{2}$ hydrolysis reaction (step 2) that operates at a temperature range of $350-450^{\circ} \mathrm{C}$. The materials leaving the thermolysis reactor are oxygen gas (which is evolved over a temperature range of 450 to $530^{\circ} \mathrm{C}$ ) and molten $\mathrm{CuCl}$. In the thermolysis reactor, the decomposition of $\mathrm{Cu}_{2} \mathrm{OCl}_{2}$ to oxygen and molten $\mathrm{CuCl}$ is an endothermic reaction requiring a reaction heat of $129.2 \mathrm{~kJ} / \mathrm{mol}$ and a temperature of $530^{\circ} \mathrm{C}$, which is the highest temperature in the $\mathrm{Cu}-\mathrm{Cl}$ cycle. Thus, heat must be added to increase the temperature of the bulk inside the reactor. The total amount of heat required is the sum of reaction heat and the heat required to raise the reactant temperature from $375^{\circ} \mathrm{C}$ (average temperature of solid particles from the hydrolysis reaction) to $530^{\circ} \mathrm{C}$ [2].

There are many studies in the literature about hydrogen production copper-chlorine $(\mathrm{Cu}-\mathrm{Cl})$ cycle. Ikeda and Kaye [5] have investigated the thermochemical properties of $\mathrm{Cu}_{2} \mathrm{OCl}_{2}$ by developing a method that uses a stoichiometric amounts of $\mathrm{CuO}$ and $\mathrm{CuCl}_{2}$ instead of $\mathrm{Cu}_{2} \mathrm{OCl}_{2}$ because of its commercial unavailability. Trevani et al. [6] have also examined the thermochemical properties of $\mathrm{Cu}_{2} \mathrm{OCl}_{2}$ by using an easy scalable method to produce pure samples of copper oxychloride with larger amounts. Zamfirescu et al. [7] have investigated the thermo physical properties of copper compounds in the $\mathrm{Cu}$ $\mathrm{Cl}$ cycle such as; $\mathrm{Cu}_{2} \mathrm{OCl}_{2}, \mathrm{CuO}, \mathrm{CuCl}_{2}$ and $\mathrm{CuCl}$. Since there is no previous available data related to the thermal conductivity and dynamic viscosity of molten $\mathrm{CuCl}$, they have used estimations to evaluate these properties.

Marin [1] has studied experimentally and theoretically the scale-up of the $\mathrm{CuO}^{*} \mathrm{CuCl}_{2}$ decomposition reactor. $\mathrm{He}$ has determined the endothermic reaction rate of the decomposition process, and solved numerically, the conservation and chemical reaction equations for a suddenly immersed particle in a viscous medium. Abdulrahman et al. [8], have studied the scale up of the oxygen reactor in the $\mathrm{Cu}-\mathrm{Cl}$ cycle from the perspective of material balance for different hydrogen production rates and different residence times. They have investigated in details the factors that influence the size of the oxygen reactor, 
such as; solid particles characteristics (size, shape and concentration), oxygen bubbles, reactor heating rate and fouling. Abdulrahman $[9,2,3]$, has investigated the thermal scale up analyses of the oxygen continuous stirred tank reactor (CSTR), by using indirect heat transfer methods, such as; a half pipe jacket [2], and an internal helical tube [3].

The design and scale-up of the thermolysis reactor must be studied from different perspectives, such as; kinetics, hydrodynamics, mass and heat transfer. In order to scale up the thermolysis reactor from the perspectives of the hydrodynamics and heat transfer, it is necessary to conduct some of the experimental works to describe the hydrodynamic and thermal behaviors. Experimentally, there are some challenges in using the actual products of the thermolysis reactor $\left(\mathrm{O}_{2}\right.$ and $\mathrm{CuCl})$ at the operating conditions of the thermolysis reactor. The challenges are; 1$)$ the cuprous chloride $(\mathrm{CuCl})$ has a high melting temperature of $430^{\circ} \mathrm{C}, 2$ ) the colour of $\mathrm{CuCl}$ after melting is non-transparent dark grey, which makes it difficult to see oxygen bubbles inside it, 3) the cuprous chloride molten salt is very corrosive, 4) Oxygen gas is a strong oxidizing agent which will quickly combust materials, and 5) high temperature process.

It is apparent that a need exists for a technique whereby the types of the materials and the operating temperature are replaced with others that can be treated easily and safely in the experiments. Also, the alternative materials must simulate the industrial conditions of the thermolysis reactor from the perspectives of hydrodynamics and heat transfer. The present paper is directed toward providing such a technique by providing a method and a system for the proper and safe run of the hydrodynamic and heat transfer experiments in the studies of the thermolysis reactor scale up. This paper investigates a commercially practicable setup for the experiments of a difficult-to-handle setup by providing alternative materials that have similar hydrodynamic and heat transfer behaviours of the actual products in the thermolysis reactor.

\section{Material Simulation of the Oxygen Reactor}

\subsection{Dimensional Analyses}

In the studies of the thermolysis reactor, the interested particular physical quantity, in heat transfer studies is the volumetric heat transfer coefficient $\left(U_{V}\right)$. This means that the "dependent variable" in the studies of the heat transfer in the thermolysis reactor is $\left(U_{V}\right)$. The first step in dimensional analysis is to specify the independent parameters [10] that have significant effect on the value of $\left(U_{V}\right)$. A total of 13 parameters $(n=13)$ are involved in the problem of $U_{V}$. These parameters include gas and liquid properties (e.g., density, dynamic viscosity, surface tension, thermal conductivity, and specific heat), reactor geometry (e.g., reactor height and diameter), and flow conditions (e.g., superficial gas velocity). The functional equation of the volumetric heat transfer coefficient in terms of the complete independent parameters can be written as;

$$
U_{V}=f\left(\rho_{l}, \rho_{g}, \mu_{l}, \mu_{g}, \sigma, U_{g s}, C_{p, l}, C_{p, g}, k_{l}, k_{g} D_{R}, H_{R}\right)
$$

where $\rho$ is the density, $\mu$ is the dynamic viscosity, $\sigma$ is the surface tension, $U_{g s}$ is the superficial gas velocity, $C_{p}$ is the specific heat, $k$ is the thermal conductivity, $D_{R}$ and $H_{R}$ are the reactor diameter and height respectively, and the subscripts $l$ and $g$ denotes to the liquid and gas respectively. The set of parameters in the right side of Eq. (1) is complete and independent. By using Buckingham's pi theorem, Eq. (1) can be converted in terms of dimensionless groups to;

$$
N u_{V}=f\left(\frac{\rho_{g}}{\rho_{l}}, \frac{\mu_{g}}{\mu_{l}}, \frac{k_{g}}{k_{l}}, \frac{C_{p, g}}{C_{p, l}}, R e_{l}, W e_{l}, P r_{l}, \frac{H_{R}}{D_{R}}\right)
$$

Since the objective of this dimensional analysis is to choose alternative materials for the actual thermolysis reactor materials, then, the dimensions of the reactor (e.g. $H_{R}$ and $D_{R}$ ) can be fixed in the dimensional analysis and the materials properties are changed. Thus, the number of parameters that actually vary from case to case will be 11 , not 13 , and the dimensionless group that can be omitted from Eq. (2) is $\frac{H_{R}}{D_{R}}$. In this case Eq. (2) will be; 


$$
N u_{V}=f\left(\frac{\rho_{g}}{\rho_{l}}, \frac{\mu_{g}}{\mu_{l}}, \frac{k_{g}}{k_{l}}, \frac{C_{p, g}}{C_{p, l}}, R e_{l}, \frac{R e_{l}^{2}}{W e_{l}}, P r_{l}\right)
$$

The functional equation (Eq. (3)) can be written as;

$$
N u_{V}=C\left(\frac{\rho_{g}}{\rho_{l}}\right)^{a}\left(\frac{\mu_{g}}{\mu_{l}}\right)^{b}\left(\frac{k_{g}}{k_{l}}\right)^{c}\left(\frac{C_{p, g}}{C_{p, l}}\right)^{d}\left(R e_{l}\right)^{e}\left(\frac{R e_{l}^{2}}{W e_{l}}\right)^{f}\left(P r_{l}\right)^{g}
$$

where $C, a, b, c, d, e, f$ and $g$ are constants that can be determined from experiments. From Eq. (4), it can be seen that $N u_{V}$ depends on both hydrodynamic and heat transfer parameters. For hydrodynamic studies, the effect of heat transfer parameters, such as $k_{g}, k_{l}, C_{p, g}, C_{p, l}$ and $U_{V}$, are neglected. By repeating the same procedure of dimensional analysis of $N u_{V}$ on gas holdup $\left(\alpha_{g}\right)$ and flow regime transition Reynolds number $\left(R e_{g-t r a n s}\right)$, they can be calculated as;

$$
\begin{gathered}
\alpha_{g}=C\left(\frac{\rho_{g}}{\rho_{l}}\right)^{a}\left(\frac{\mu_{g}}{\mu_{l}}\right)^{b}\left(R e_{l}\right)^{c}\left(\frac{R e_{l}^{2}}{W e_{l}}\right)^{d}, \\
R e_{g-\text { trans }}=C\left(\frac{\rho_{g}}{\rho_{l}}\right)^{a}\left(\frac{\mu_{g}}{\mu_{l}}\right)^{b}\left(R e_{l}\right)^{c}\left(\frac{R e_{l}^{2}}{W e_{l}}\right)^{d},
\end{gathered}
$$

where the constant $C$ and the exponents $a, b, c$ and $d$ have different values in Eq. (4), (5) and (6) and;

$$
R e_{g-\text { trans }}=\frac{\rho_{g} U_{g-\text { trans }} D_{R}}{\mu_{g}}
$$

From Eq. (5) and (6), it can be seen that these equations have the same form of Eq. (4) when omitting heat transfer dimensionless groups $\left(\frac{k_{g}}{k_{l}}, \frac{C_{p, g}}{C_{p, l}}, P r_{l}\right.$, and $\left.U_{V}\right)$. In the thermolysis reactor, in order to find alternative materials that have similar effects of the actual materials for heat transfer and hydrodynamic studies, each dimensionless group in Eq. (4) for heat transfer and Eq. (5) and (6) for hydrodynamic, must have the same value for both the actual and alternative materials, except $R e_{l}$ which is adjustable by $U_{g s}$.

After checking the physical properties of many liquids and gases, it was found that the alternative materials that can be used in the experiments instead of $\mathrm{CuCl}$ molten salt at $530^{\circ} \mathrm{C}$ and oxygen gas at $530^{\circ} \mathrm{C}$ are liquid water at $22^{\circ} \mathrm{C}$ and helium gas at $90^{\circ} \mathrm{C}$ respectively. The advantages of these materials are the availability and the safe usage in the lab. The experimental and CFD analyses of the thermal hydraulics of liquid water at $22^{\circ} \mathrm{C}$ and helium gas at $90^{\circ} \mathrm{C}$ have been investigated in details by Abdulrahman [11-16].

\subsection{Properties of Actual and Experimental Materials}

Table 1 indicates the physical properties of both the actual and experimental fluids. The value of the surface tension of molten $\mathrm{CuCl}$ in contact with air is equal to $0.092 \mathrm{~N} / \mathrm{m}$ at the melting temperature of $\mathrm{CuCl}\left(450^{\circ} \mathrm{C}\right)$ [17]. Since the surface tension decreases approximately linearly with temperature and is equal to zero at the critical temperature of the liquid, a linear function of $\mathrm{CuCl}$ surface tension with temperature can be derived as follows;

$$
\sigma_{C u C l}=0.115-5.076 \times 10^{-5} T
$$


The predicted value of the critical temperature that is used in deriving Eq. (8) with 50\% accuracy is equal to $2435 \mathrm{~K}$ [18, 7]. There is no change in the value of the surface tension of pure liquid light water $\left(\mathrm{H}_{2} \mathrm{O}\right)$ in the presence of the non-polar (i.e. non-interacting) helium gas in comparison to air or other relatively inert gases. At the atmospheric pressure, helium has a quite low solubility in water $\left(8.53 \mathrm{~mL} / \mathrm{L}\right.$ at $21.7^{\circ} \mathrm{C}$ or $0.00152 \mathrm{~g} / \mathrm{L}$ at $\left.20^{\circ} \mathrm{C}\right)$. Therefore, helium gas is not able to induce measurable surface tension changes in the polar liquid water of more than $0.1 \mathrm{mN} / \mathrm{m}$ under STP, which is by the way, the repeatability and reproducibility of most simple tensiometers or pendant drop devices [19].

Table 1: Physical properties of the actual and experimental materials.

\begin{tabular}{|l|c|c|c|c|}
\hline \multirow{2}{*}{ Physical Property } & \multicolumn{2}{|c|}{ Actual Materials } & \multicolumn{2}{c|}{ Experimental Materials } \\
\cline { 2 - 5 } & $\begin{array}{c}\text { CuCl molten salt } \\
(\mathbf{T = 5 3 0} \mathbf{C})\end{array}$ & $\begin{array}{c}\text { Oxygen gas } \\
\left(\mathbf{T = 5 3 0} \mathbf{5}^{\circ} \mathbf{C}\right)\end{array}$ & $\begin{array}{c}\text { Water } \\
\left(\mathbf{T = 2 2}^{\circ} \mathbf{C}\right)\end{array}$ & $\begin{array}{c}\text { Helium gas } \\
(\mathbf{T = 9 0} \mathbf{C})\end{array}$ \\
\hline Density $(\rho)$ & $3692[7]$ & 0.4857 & $997.8[20]$ & 0.1344 \\
\hline Dynamic viscosity $(\mu)$ & $0.002045[7]$ & $4.25 \mathrm{E}-05[21]$ & $0.000975[22]$ & $2.267 \mathrm{E}-05[23]$ \\
\hline Specific heat $\left(C_{p}\right)$ & $650.85[7]$ & $1047.25[24]$ & $4180.6[25]$ & $5193[24]$ \\
\hline Thermal conductivity $(k)$ & $0.2[7]$ & $0.0605[21]$ & $0.6[26]$ & $0.1687[23]$ \\
\hline Surface tension $(\sigma)$ & 0.0867 & - & $0.0724[27]$ & - \\
\hline
\end{tabular}

\section{Results and Discussion}

Table 2 shows the values of each dimensionless group of Eq. (4) for both the actual and experimental fluids in addition to the percentage of error that is calculated for each dimensionless group. From Table 2, it can be shown that the maximum percentage error that is produced from using water liquid at $22^{\circ} \mathrm{C}$ and helium gas at $90^{\circ} \mathrm{C}$ instead of molten $\mathrm{CuCl}$ and oxygen gas at $530^{\circ} \mathrm{C}$ is coming from the specific heat and is equal to $22.8 \%$.

Table 2: Dimensionless groups of the actual and experimental materials and the percentage of error.

\begin{tabular}{|c|c|c|c|}
\hline Dimensionless Group & Actual Materials & Experimental Materials & Error\% \\
\hline$\frac{\rho_{g}}{\rho_{l}}$ & 0.0001315 & 0.000135 & 2.66 \\
\hline$\frac{\mu_{g}}{\mu_{l}}$ & 0.02078 & 0.023 & 10.68 \\
\hline$\frac{C_{p, g}}{C_{p, l}}$ & 1.609 & 1.242 & 22.8 \\
\hline$\frac{k_{g}}{k_{l}}$ & 0.302 & 0.28 & 7.285 \\
\hline$P r_{l}$ & 6.66 & 6.779 & 1.786 \\
\hline$\frac{R e_{l}^{2}}{W e_{l}}$ & $76473868\left(D_{R}=1 m\right)$ & $76085070\left(D_{R}=1 m\right)$ & 0.508 \\
\hline
\end{tabular}

\section{Conclusions}

This paper seeks to provide a solution to the problems and challenges associated with the use of the actual materials in the thermolysis reactor by selecting alternative materials. The materials have to be suitable for use in the lab and must give similar effects of the actual materials in the hydrodynamic and heat transfer studies. By using dimensional analysis of 
Buckingham pi theorem, it was found that the alternative materials that can be used in the experiments instead of $\mathrm{CuCl}$ molten salt at $530^{\circ} \mathrm{C}$ and oxygen gas at $530^{\circ} \mathrm{C}$ are liquid water at $22^{\circ} \mathrm{C}$ and helium gas at $90^{\circ} \mathrm{C}$ respectively. The of these materials are the availability and the safe usage in the lab, in addition to the low temperature of the experimental run.

\section{References}

[1] G. D. Marin, "Kinetics and transport phenomena in the chemical decomposition of copper oxychloride in the thermochemical Cu-Cl cycle," Ph.D. dissertation, Dept. Mech. Eng., UOIT, Oshawa, ON, Canada, 2012.

[2] M. W. Abdulrahman, "Similitude for thermal scale-up of a multiphase thermolysis reactor in the cu-cl cycle of a hydrogen production," World Academy of Science, Engineering and Technology, International Journal of Electrical, Computer, Energetic, Electronic and Communication Engineering, vol. 10, no. 5, pp. 567-573, 2016.

[3] M. W. Abdulrahman, "Heat transfer analysis of a multiphase oxygen reactor heated by a helical tube in the $\mathrm{Cu}-\mathrm{Cl}$ cycle of a hydrogen production," World Academy of Science, Engineering and Technology, International Journal of Mechanical, Aerospace, Industrial, Mechatronic and Manufacturing Engineering, vol. 10, no. 6, pp. 1018-1023, 2016.

[4] M. W. Abdulrahman, "Analysis of the thermal hydraulics of a multiphase oxygen production reactor in the $\mathrm{Cu}-\mathrm{Cl}$ cycle,” Ph.D. dissertation, Dept. Mech. Eng., UOIT, Oshawa, ON, Canada, 2016.

[5] B. M. Ikeda and M. H. Kaye, "Thermodynamic Properties in the Cu-Cl- O-H System," in Proceedings of the 7th International Conference on Nuclear and Radiochemistry, Budapest, Hungary, 2008.

[6] L. Trevani, "The copper-Cloride cycle: synthesis and characterization of copper oxychloride," in Proceedings of the Hydrogen and Fuel Cells International conference and Exhibition, Vancouver, BC, Canada, 2011.

[7] C. Zamfirescu, I. Dincer, and G. F. Naterer, "Thermophysical properties of copper compounds in copper-chlorine thermochemical water splitting cycles," International Journal of Hydrogen Energy, vol. 35, pp. 4839-4852, 2010.

[8] M. W. Abdulrahman, Z. Wang, and G. F. Naterer, "Scale-up analysis of three-phase oxygen reactor in the $\mathrm{Cu}-\mathrm{Cl}$ thermochemical cycle of hydrogen production," in Proceedings of the EIC Climate Change Technology Conference (CCTC2013), Montreal, QC, Canada, 2013.

[9] M. W. Abdulrahman, Z. Wang, and G. F. Naterer, "Thermohydraulics of a Thermolysis Reactor and Heat Exchangers in the $\mathrm{Cu}-\mathrm{Cl}$ Cycle of Nuclear Hydrogen Production," in Proceedings of the 5th World Hydrogen Technologies Convention (WHTC 2013), China, 2013.

[10] A. A. Sonin, The physical basis of dimensional analysis ( $2^{\text {nd }}$ ed.), Department of Mechanical Engineering, Cambridge, 2001.

[11] M. W. Abdulrahman, "Experimental studies of direct contact heat transfer in a slurry bubble column at high gas temperature of a helium-water-alumina system," Applied Thermal Engineering, vol. 91, pp. 515-524, 2015.

[12] M. W. Abdulrahman, "Experimental studies of gas holdup in a slurry bubble column at high gas temperature of a helium- water- alumina system," Chemical Engineering Research and Design, vol. 109, pp. 486-494, 2016.

[13] M. W. Abdulrahman, "Experimental studies of the transition velocity in a slurry bubble column at high gas temperature of a helium-water-alumina system," Experimental Thermal and Fluid Science, vol. 74, pp. 404-410, 2016.

[14] M. W. Abdulrahman, "CFD simulations of direct contact volumetric heat transfer coefficient in a slurry bubble column at a high gas temperature of a helium-water-alumina system," Applied Thermal Engineering, vol. 99, pp. 224-234, 2016.

[15] M. W. Abdulrahman, "CFD Analysis of Temperature Distributions in a Slurry Bubble Column with Direct Contact Heat Transfer," in Proceedings of the 3rd International Conference on Fluid Flow, Heat and Mass Transfer (FFHMT'16), Ottawa, ON, Canada, 2016.

[16] M. W. Abdulrahman, "Direct contact heat transfer in the thermolysis reactor of hydrogen production $\mathrm{Cu}-\mathrm{Cl}$ cycle," US Patent App. 10/059, 586, 2018

[17] G. J. Janz, "Thermodynamic and transport properties for molten salts: Correlation equations for critically evaluated density, surface tension, electrical conductance, and viscosity data," Journal of Physical and Chemical Reference Data, vol. 17, no. 2, 1988. 
[18] R. L. Rowley, W. V. Wilding, J. L. Oscarson, Y. Yang, N. A. Zundeland, and T. P. Daubert, DIPPR data compilation of pure chemical properties. New York: Taylor \& Francis, 2004.

[19] T. J. Morrison, and N. B. Johnstone, "Solubilities of the inert gases in water," Journal of Chemical Society, pp. 34413446.

[20] S. C. McCutcheon, J. L. Martin, and T. O. Barnwell, Water quality. In D. R. Maidment (Editor), Handbook of Hydrology. New York: McGraw-Hill, 1993.

[21] E. W. Lemmon, and R. T. Jacobsen, "Viscosity and thermal conductivity equations for nitrogen, oxygen, argon, and air," International Journal of Thermophysics, vol. 25, no. 1, pp. 21-69, 2004.

[22] R. C. Reid, J. M. Prausnitz, and B. E. Poling, Properties of gases and liquids. New York: McGraw-Hill, 1987.

[23] H. Petersen, "The properties of helium: Density, specific heats, viscosity, and thermal conductivity at pressures from 1 to 100 bar and from room temperature to about 1800 K," Risö Report No. 224. Danish atomic energy commission research establishment Risö, 1970.

[24] C. Borgnakke, and R. E. Sonntag, Fundamentals of Thermodynamics (7 $7^{\text {th }}$ ed.). USA: John Wiley \& Sons, Inc., 2009.

[25] Osborne, Stimson, and B. Ginnings, Handbook of Chemistry and Physics of S. Jour. Res., 23, 238. In, 53rd ed., Cleveland, Ohio, D128 (1972-1973), 1939.

[26] M. L. V. Ramires, A. Nieto de Castro, Y. Nagasaka, A. Nagashima, M. J. Assael, W. A. Wakeham, "Standard reference data for the thermal conductivity of water," American Institute of Physics and the American Chemical society, 1994.

[27] N. B. Vargaftik, B. N. Volkov, and L. D. Voljak, "International tables of the surface tension of water," Journal of Physical and Chemical Reference Data, Moscow Aviation Institute, Moscow, U.S.S.R. vol. 12, no. 3, pp. 817-820, 1983. 